\title{
Optimization of machining techniques - A retrospective and literature review
}

\author{
AMAN AGGARWAL ${ }^{1}$ and HARI SINGH ${ }^{2 *}$ \\ ${ }^{1}$ Dept. of Mechanical and Automation Engineering, Maharaja Agrasen Institute \\ of Technology, Sector 22, Rohini, Delhi 110 085, India \\ ${ }^{2}$ Department of Mechanical Engineering, National Institute of Technology, \\ Kurukshetra 136 119, India \\ e-mail: hsingh_nitk@rediffmail.com
}

MS received 24 February 2005; revised 18 August 2005

\begin{abstract}
In this paper an attempt is made to review the literature on optimizing machining parameters in turning processes. Various conventional techniques employed for machining optimization include geometric programming, geometric plus linear programming, goal programming, sequential unconstrained minimization technique, dynamic programming etc. The latest techniques for optimization include fuzzy logic, scatter search technique, genetic algorithm, Taguchi technique and response surface methodology.
\end{abstract}

Keywords. Machining optimization; goal programming; fuzzy logic; genetic algorithms; Taguchi technique; response surface methodology.

\section{Introduction}

It has long been recognized that conditions during cutting, such as feed rate, cutting speed and depth of cut, should be selected to optimize the economics of machining operations, as assessed by productivity, total manufacturing cost per component or some other suitable criterion. Taylor (1907) showed that an optimum or economic cutting speed exists which could maximize material removal rate. Manufacturing industries have long depended on the skill and experience of shop-floor machine-tool operators for optimal selection of cutting conditions and cutting tools. Considerable efforts are still in progress on the use of handbookbased conservative cutting conditions and cutting tool selection at the process planning level. The most adverse effect of such a not-very scientific practice is decreased productivity due to sub-optimal use of machining capability.

The need for selecting and implementing optimal machining conditions and the most suitable cutting tool has been felt over the last few decades. Despite Taylor's early work on establishing optimum cutting speeds in single pass turnings, progress has been slow since all the

\footnotetext{
*For correspondence
} 
process parameters need to be optimized. Furthermore, for realistic solutions, the many constraints met in practice, such as low machine tool power, torque, force limits and component surface roughness, must be over come.

The non-availability of the required technological performance equation represents a major obstacle to implementation of optimized cutting conditions in practice. This follows since extensive testing is required to establish empirical performance equations for each tool coating-work material combination for a given machining operation, which can be quite expensive when a wide spectrum of machining operations is considered. Further the performance equations have to be updated as new coatings, new work materials and new cutting tools are introduced. While comprehensive sets of equations are found in some Chinese and Russian handbooks (Ai et al 1966; Ai \& Xiao 1985; Kasilova \& Mescheryakov 1985), as well in the American handbook (ASME 1952) and Kroneberg's (1966), textbook most authors have not included discussions on the more modern tools, new work materials and tool coatings. Difficulties are experienced in locating the empirical performance equations for modern tool designs because these are hidden under computerized databases in proprietary software (Sandvik 1981), as noted in recent investigations (Armarego \& Ostafiev 1998; Ostafiev 1999).

\section{Review of traditional optimization techniques}

Traditionally, the selection of cutting conditions for metal cutting is left to the machine operator. In such cases, the experience of the operator plays a major role, but even for a skilled operator it is very difficult to attain the optimum values each time. Machining parameters in metal turning are cutting speed, feed rate and depth of cut. The setting of these parameters determines the quality characteristics of turned parts. Following the pioneering work of Taylor (1907) and his famous tool life equation, different analytical and experimental approaches for the optimization of machining parameters have been investigated.

Gilbert (1950) studied the optimization of machining parameters in turning with respect to maximum production rate and minimum production cost as criteria. Armarego \& Brown (1969) investigated unconstrained machine-parameter optimization using differential calculus. Brewer \& Rueda (1963) carried out simplified optimum analysis for non-ferrous materials. For cast iron $(\mathrm{CI})$ and steels, they employed the criterion of reducing the machining cost to a minimum. A number of nomograms were worked out to facilitate the practical determination of the most economic machining conditions. They pointed out that the moredifficult-to-machine materials have a restricted range of parameters over which machining can be carried out and thus any attempt at optimizing their costs is artificial.

Brewer (1966) suggested the use of Lagrangian multipliers for optimization of the constrained problem of unit cost, with cutting power as the main constraint. Bhattacharya et al (1970) optimized the unit cost for turning, subject to the constraints of surface roughness and cutting power by the use of Lagrange's method. Walvekar \& Lambert (1970) discussed the use of geometric programming to selection of machining variables. They optimized cutting speed and feed rate to yield minimum production cost. Petropoulos (1973) investigated optimal selection of machining rate variables, viz. cutting speed and feed rate, by geometric programming. A constrained unit cost problem in turning was optimized by machining SAE 1045 steel with a cemented carbide tool of ISO P-10 grade.

Sundaram (1978) applied a goal-programming technique in metal cutting for selecting levels of machining parameters in a fine turning operation on AISI 4140 steel using cemented tungsten carbide tools. Ermer \& Kromodiharajo (1981) developed a multi-step mathematical 
model to solve a constrained multi-pass machining problem. They concluded that in some cases with certain constant total depths of cut, multi-pass machining was more economical than single-pass machining, if depth of cut for each pass was properly allocated. They used high speed steel (HSS) cutting tools to machine carbon steel.

Hinduja et al (1985) described a procedure to calculate the optimum cutting conditions for turning operations with minimum cost or maximum production rate as the objective function. For a given combination of tool and work material, the search for the optimum was confined to a feed rate versus depth-of-cut plane defined by the chip-breaking constraint. Some of the other constraints considered include power available, work holding, surface finish and dimensional accuracy.

Tsai (1986) studied the relationship between the multi-pass machining and single-pass machining. He presented the concept of a break-even point, i.e. there is always a point, a certain value of depth of cut, at which single-pass and double-pass machining are equally effective. When the depth of cut drops below the break-even point, the single-pass is more economical than the double-pass, and when the depth of cut rises above this break-even point, double-pass is better. Carbide tools are used to turn the carbon steel work material.

Gopalakrishnan \& Khayyal (1991) described the design and development of an analytical tool for the selection of machine parameters in turning. Geometric programming was used as the basic methodology to determine values for feed rate and cutting speed that minimize the total cost of machining SAE 1045 steel with cemented carbide tools of ISO P-10 grade. Surface finish and machine power were taken as the constraints while optimizing cutting speed and feed rate for a given depth of cut.

Agapiou (1992) formulated single-pass and multi-pass machining operations. Production cost and total time were taken as objectives and a weighting factor was assigned to prioritize the two objectives in the objective function. He optimized the number of passes, depth of cut, cutting speed and feed rate in his model, through a multi-stage solution process called dynamic programming. Several physical constraints were considered and applied in his model. In his solution methodology, every cutting pass is independent of the previous pass, hence the optimality for each pass is not reached simultaneously.

Prasad et al (1997) reported the development of an optimization module for determining process parameters for turning operations as part of a PC-based generative CAPP system. The work piece materials considered in their study include steels, cast iron, aluminium, copper and brass. HSS and carbide tool materials are considered in this study. The minimization of production time is taken as the basis for formulating the objective function. The constraints considered in this study include power, surface finish, tolerance, work piece rigidity, range of cutting speed, maximum and minimum depths of cut and total depth of cut. Improved mathematical models are formulated by modifying the tolerance and work piece rigidity constraints for multi-pass turning operations. The formulated models are solved by the combination of geometric and linear programming techniques.

\section{Latest techniques}

The latest techniques for optimization include fuzzy logic, scatter search technique, genetic algorithm, Taguchi technique and response surface methodology.

\subsection{Fuzzy logic}

Fuzzy logic has great capability to capture human commonsense reasoning, decision-making and other aspects of human cognition. Kosko (1997) shows that it overcomes the limitations 
of classic logical systems, which impose inherent restrictions on representation of imprecise concepts. Vagueness in the coefficients and constraints may be naturally modelled by fuzzy logic. Modelling by fuzzy logic opens up a new way to optimize cutting conditions and also tool selection.

3.1a Methodology: As per Klir \& Yuan (1998) fuzzy logic involves a fuzzy interference engine and a fuzzification-defuzzification module. Fuzzification expresses the input variables in the form of fuzzy membership values based on various membership functions. Governing rules in linguistic form, such as if cutting force is high and machining time is high, then tool wear is high, are formulated on the basis of experimental observations. Based on each rule, inference can be drawn on output grade and membership value. Inferences obtained from various rules are combined to arrive at a final decision. The membership values thus obtained are defuzzified using various techniques to obtain true value, say of flank wear.

\subsection{Genetic algorithm (GA)}

These are the algorithms based on mechanics of natural selection and natural genetics, which are more robust and more likely to locate global optimum. It is because of this feature that GA goes through solution space starting from a group of points and not from a single point. The cutting conditions are encoded as genes by binary encoding to apply GA in optimization of machining parameters. A set of genes is combined together to form chromosomes, used to perform the basic mechanisms in GA, such as crossover and mutation.

Crossover is the operation to exchange some part of two chromosomes to generate new offspring, which is important when exploring the whole search space rapidly. Mutation is applied after crossover to provide a small randomness to the new chromosomes. To evaluate each individual or chromosome, the encoded cutting conditions are decoded from the chromosomes and are used to predict machining performance measures. Fitness or objective function is a function needed in the optimization process and selection of next generation in genetic algorithm. Optimum results of cutting conditions are obtained by comparison of values of objective functions among all individuals after a number of iterations. Besides weighting factors and constraints, suitable parameters of GA are required to operate efficiently. GA optimization methodology is based on machining performance predictions models developed from a comprehensive system of theoretical analysis, experimental database and numerical methods. The GA parameters along with relevant objective functions and set of machining performance constraints are imposed on GA optimization methodology to provide optimum cutting conditions.

3.2a Implementation of GA: First of all, the variables are encoded as $n$-bit binary numbers assigned in a row as chromosome strings. To implement constraints in GA, penalties are given to individuals out of constraint. If an individual is out of constraint, its fitness will be assigned as zero. Because individuals are selected to mate according to fitness value, zero fitness individuals will not become parents. Thus most individuals in the next generation are ensured in feasible regions bounded by constraints.

The GA is initialized by randomly selecting individuals in the full range of variables. Individuals are selected to be parents of the next generation according to their fitness value. The larger the fitness value, the greater their possibility of being selected as parents. Wang \& Jawahir (2004) have used this technique for optimization of milling machine parameters. Kuo \& Yen (2002) have used a genetic algorithm based parameter tuning algorithm for multidimensional motion control of a computer numerical control machine tool. 


\subsection{Scatter search technique (SS)}

This technique originates from strategies for combining decision rules and surrogate constraints. SS is completely generalized and problem-independent since it has no restrictive assumptions about objective function, parameter set and constraint set. It can be easily modified to optimize machining operation under various economic criteria and numerous practical constraints. It can obtain near-optimal solutions within reasonable execution time on PC. Potentially, it can be extended as an on-line quality control strategy for optimizing machining parameters based on signals from sensors. Chen \& Chen (2003) have done extensive work on this technique.

3.3a Methodology: First of all, machining models are required to determine the optimum machining parameters including cutting speed, feed rate and depth of cut, in order to minimize unit production cost. Unit production cost can be divided into four basic cost elements:

- Cutting cost by actual cut in time

- Machine idle cost due to loading and unloading operation and idling tool motion cost

- Tool replacement cost

- Tool cost

For the optimization of unit production cost, practical constraints which present the state of machining processes need to be considered. The constraints imposed during machining operations are:

- Parameter constraint - Ranges of cutting speed, feed rate and depth of cut

- Tool life constraint - Allowable values of flank wear width and crater wear depth

- Operating constraint - Maximum allowable cutting force, power available on machine tool and surface finish requirement.

An optimization model for multi-pass turning operation can be formulated. The multipass turning model is a constrained nonlinear programming problem with multiple variables (machining variables). The initial solution for SS is picked in a random way. The user-specified parameters have to be given. The experimentation can be run on a PC with Pentium800Mhz processor. The computational results validate the advantage of SS in terms of solution quality and computational requirement.

\subsection{Taguchi technique}

Genichi Taguchi is a Japanese engineer who has been active in the improvement of Japan's industrial products and processes since the late 1940s. He has developed both the philosophy and methodology for process or product quality improvement that depends heavily on statistical concepts and tools, especially statistically designed experiments. Many Japanese firms have achieved great success by applying his methods. Wu (1982) has reported that thousands of engineers have performed tens of thousands of experiments based on his teachings. Sullivan (1987) reports that Taguchi has received some of Japan's most prestigious awards for quality achievement, including the Deming prize. In 1986, Taguchi received the most prestigious prize from the International Technology Institute - The Willard F. Rockwell Medal for Excellence in Technology. Taguchi's major contribution has involved combining engineering and statistical methods to achieve rapid improvements in cost and quality by optimizing product design and manufacturing processes. 
Barker (1990) reported that since 1983, after Taguchi's association with the top companies and institutes in USA (AT \& T Bell Laboratories, Xerox, Lawrence Institute of Technology (LIT), Ford Motor Company etc.), his methods have been called a radical approach to quality, experimental design and engineering. Sullivan (1987) reported that the term "Taguchi methods" (TM) refers to the parameter design, tolerance design, quality loss function, on-line quality control, design of experiments using orthogonal arrays, and methodology applied to evaluate measuring systems.

Pignatiello (1988) identifies two separate aspects of the Taguchi methods: the strategy of Taguchi and the tactics of Taguchi. Taguchi tactics refer to the collection of specific methods and techniques used by Genichi Taguchi, and Taguchi strategy is the conceptual framework or structure for planning a product or process design experiment.

Ryan (1988) and Benton (1991) reported that Taguchi addresses design and engineering (off-line) as well as manufacturing (on-line) quality. This fundamentally differentiates TM from statistical process control (SPC), which is purely an on-line quality control method. Taguchi's ideas can be distilled into two fundamental concepts:

(a) Quality losses must be defined as deviations from targets, not conformance to arbitrary specifications (Benton 1991).

(b) Achieving high system-quality levels economically requires quality to be designed into the product. Quality is designed, not manufactured, into the product (Daetz 1987; Taguchi 1989).

Lin et al (1990) stated that Taguchi methods represent a new philosophy. Quality is measured by the deviation of a functional characteristic from its target value. Noises (uncontrolled variables) can cause such deviations resulting in loss of quality. Taguchi methods seek to remove the effect of noises.

Taguchi (1989) described that quality engineering encompasses all stages of product/process development: system design, parameter design, and tolerance design. Byrne \& Taguchi (1987), however, pointed out that the key element for achieving high quality and low cost is parameter design. Through parameter design, levels of product and process factors are determined, such that the product's functional characteristics are optimized and the effect of noise factors is minimized. Kackar \& Shoemaker (1986) observed that parameter design reduces performance variation by reducing the influence of the sources of variation rather than by controlling them, it is thus a very cost-effective technique for improving engineering design.

3.4a Applications: Chanin et al (1990) remarked that Japanese companies such as Nippon Denso, NEC, and Fugitsu have become world economic competitors by using Taguchi's approach which has potential for saving experimental time and cost on product or process development, as well as quality improvement. Kacker \& Shoemaker (1986), Phadke (1986), and Pao et al (1985) pointed out that the methodology advocated by Taguchi has been applied within AT \& $\mathrm{T}$ to a variety of problems ranging from IC fabrication to response time optimization of a UNIX system since Taguchi's first visit to AT \& T Bell Laboratories in 1980. Ghosh (1990) remarked that Taguchi's ideas are also being used in many others US companies such as Ford and Xerox. There are also many courses on robust parameter design offered by organizations like American Supplier Institute, Rochester Institute of Technology, and the Center for Quality and Productivity Improvement at the University of Wisconsin in Madison. The American Supplier Institute also has an annual symposium where case studies on the application of the Taguchi Methods are presented. 
The Casting Division of Ford Motors has been one of the pioneers in training employees in Taguchi's methods since 1983. Enright \& Price (1987) have cited a few case studies conducted in the Casting Division of Ford Motors and illustrated the depth and impact on the product quality and productivity that has occurred since the decision to implement Taguchi's approach was made. Moneymaker \& Hubbard (1987) have presented a case of the application of loss function concept to the quality improvement program at the Rockwell International Steel Foundry at Atchison, Kansas. Lin \& Kackar (1985) have shown how a 36-run orthogonal array design was used to improve a wave soldering process by studying 17 variables simultaneously. Kamat \& Rao (1994) have presented a case study of Taguchi optimization related to manufacturing processes for die-cast components. The use of optimal parameter combinations obtained from the analysis reduced the rejection of die-cast components by $90 \%$. Tsui (1999) presented robust design optimization for multiple characteristic problems. Robust design improves product or manufacturing process design by making the output response insensitive (robust) to difficult-to-control variations. The multivariate quality loss function considered by Pignatiello (1993) has been extended to include the smaller and the larger-the-better type characteristics. Under various assumptions, appropriate two-step procedures were developed that minimize the average multivariate loss. The proposed two-step procedure substantially reduces the dimension of the design optimization problem and allows for future changes of response target values without re-optimization. The proposed procedure was illustrated with a polysilicon deposition example. Singh \& Kumar $(2003,2004,2005)$ have applied Taguchi's technique for optimizing surface finish, tool wear, cutting force and power consumed in turning operations for machining En24 steel with titanium carbide-coated tungsten carbide inserts.

The success of many applications has demonstrated the power of Taguchi's overall approach. It is also worth mentioning that many of the specific statistical techniques he has proposed for implementing robust parameter design have generated a great deal of controversy. However, most commentators agree that Taguchi's loss function concept represents a solid contribution. Furthermore, there is general agreement that off-line experiments during the product or process design stage are of great value and the methodology is based on solid engineering principles. Reducing quality loss by designing the products and processes to be insensitive to variations in noise variables is a novel concept to statisticians and quality engineers.

\subsection{Response surface methodology (RSM)}

Experimentation and making inferences are the twin features of general scientific methodology. Statistics as a scientific discipline is mainly designed to achieve these objectives. Planning of experiments is particularly very useful in deriving clear and accurate conclusions from the experimental observations, on the basis of which inferences can be made in the best possible manner. The methodology for making inferences has three main aspects. First, it establishes methods for drawing inferences from observations when these are not exact but subject to variation, because inferences are not exact but probabilistic in nature. Second, it specifies methods for collection of data appropriately, so that assumptions for the application of appropriate statistical methods to them are satisfied. Lastly, techniques for proper interpretation of results are devised.

The advantages of design of experiments as reported by Adler et al (1975) and Johnston (1964) are as follows.

(1) Numbers of trials are reduced.

(2) Optimum values of parameters can be determined. 
(3) Assessment of experimental error can be made.

(4) Qualitative estimation of parameters can be made.

(5) Inference regarding the effect of parameters on the characteristics of the process can be made.

Cochran \& Cox (1962) quoted Box and Wilson as having proposed response surface methodology for the optimization of experiments. In many experimental situations, it is possible to represent independent factors in quantitative form. Then these factors can be thought of as having a functional relationship or response:

$$
Y=\phi\left(X_{1}, X_{2}, \ldots, X_{k}\right) \pm e_{r},
$$

between the response $Y$ and $X_{1}, X_{2}, \ldots X_{k}$ of $k$ quantitative factors. The function $\phi$ is called response surface or response function. The residual $e_{r}$ measures the experimental error. For a given set of independent variables, a characteristic surface responds. When the mathematical form of $\phi$ is not known, it can be approximated satisfactorily within the experimental region by a polynomial. The higher the degree of the polynomial the better is the correlation, though at the same time the costs of experimentation become higher.

The methodology may be applied for developing the mathematical models in the form of multiple regression equations correlating the dependent parameters such as cutting force, power consumption, surface roughness, tool life etc. with three independent parameters, viz. cutting speed, feed rate and depth of cut, in a turning process. In applying the response surface methodology, the dependent parameter is viewed as a surface to which a mathematical model is fitted. For the development of regression equations related to various quality characteristics of turned parts, the second-order response surface may be assumed as:

$$
Y=b_{o}+\sum_{i=1}^{k} b_{i} X_{i}+\sum_{i=1}^{k} b_{i i} X_{i}^{2}+\sum_{i<j=2}^{k} b_{i j} X_{i} X_{j} \pm e_{r} .
$$

This assumed surface $Y$ contains linear, squared and cross-product terms of variables $X_{i}$ 's. In order to estimate the regression coefficients a number of experimental design techniques are available. Box \& Hunter (1957) have proposed that the scheme based on central composite rotatable design fits the second-order response surfaces very accurately.

Lambert \& Taraman (1973) developed an adequate mathematical model for the cutting force acting on a carbide tool while machining SAE 1018 cold-rolled steel in a turning operation and then utilized the model in the selection of the levels of the machining variables of cutting speed, feed rate, and depth of cut, such that the rate of metal-removal could be at the highest possible value without violating some given force restriction. By using response surface methodology the three independent variables (cutting speed, feed rate and depth of cut) could be investigated simultaneously to study their effects on the cutting force, resulting in considerable saving in time and money over traditional methods of analysis.

Taraman (1974) investigated multi-machining output multi-independent variable turning research by response surface methodology. The purpose of this research was to develop a methodology that would allow determination of the cutting conditions (cutting speed, feed rate and depth of cut) such that the specified criterion for each of several machining-dependent parameters (surface finish, tool force and tool life) could be achieved simultaneously. To accomplish this, first mathematical models were developed representing the relationship between the dependent and independent variables of the process. A central composite design was used to develop the models in order to minimize the amount of experimentation. The 
models were represented by response surfaces and contours of these surfaces were obtained at different levels of each of the independent variables in planes of the other independent variables. By superimposing the contours, a proper combination of the cutting speed, feed rate and depth of cut can be selected to satisfy some specified criteria. Disposable inserts of tungsten carbide were used to turn SAE1018 cold-rolled steel.

Hassan \& Suliman (1990) presented mathematical models for the prediction of surface roughness, tool vibration, power consumption and cutting time, when turning medium carbon steel using tungsten carbide tools under dry conditions. The functional relationships of these variables and the machining-independent variables (cutting speed, feed rate and depth of cut) were established by a second-order polynomial multi-regression analysis. The surface roughness model developed was used as an objective function to establish the optimum cutting conditions while the tool vibration level, power consumption and cutting time were considered the functional constraints.

El Baradie (1993) presented a study of the development of a surface roughness model for turning grey cast iron $(154 \mathrm{BHN})$ using tipped carbide tools under dry conditions and for a constant depth of cut $(d=1.00 \mathrm{~mm})$. The mathematical model utilizing the response surface methodology was developed in terms of cutting speed, feed rate and nose radius of the cutting tool. These variables were investigated using design of experiments and utilization of the response surface methodology. The turning operation was performed on a $10 \mathrm{~h} . \mathrm{p}$. lathe. The work pieces were cast in the form of cylindrical bars $200 \mathrm{~mm}$ in diameter and approximately $500 \mathrm{~mm}$ in length. The cutting tests were carried out using a tungsten carbide insert (grade K10). Surface roughness measurements were made using a Taylor-Hobson Surtronic surface roughness measuring instrument. A first-order model covering the cutting speed range of $110-350 \mathrm{~m} / \mathrm{min}$ and a second-order model covering the cutting speed range of 80-495 $\mathrm{m} / \mathrm{min}$ are presented in this study. Contours of the surface roughness outputs were obtained in planes containing two of the independent variables. These contours were further developed to select the proper combination of the cutting speed and feed rate to increase the metal removal rate without sacrificing the quality of the surface roughness produced.

Table 1 summarizes the traditional and latest optimization techniques discussed in $\S \S 2$ and 3 for the optimization of process variables in metal machining.

\section{Conclusions}

A review of literature shows that various traditional machining optimization techniques like Lagrange's method, geometric programming, goal programming, dynamic programming etc. have been successfully applied in the past for optimizing the various turning process variables. Fuzzy logic, genetic algorithm, scatter search, Taguchi technique and response surface methodology are the latest optimization techniques that are being applied successfully in industrial applications for optimal selection of process variables in the area of machining. A review of literature on optimization techniques has revealed that there are, in particular, successful industrial applications of design of experiment-based approaches for optimal settings of process variables. Taguchi methods and response surface methodology are robust design techniques widely used in industries for making the product/process insensitive to any uncontrollable factors such as environmental variables. Japanese companies such as Nippon Denso, NEC, and Fugitsu have become world economic competitors by using the Taguchi approach that has potential for savings in experimental time and cost on product or process development and quality improvement. There is general agreement that off-line experiments 
Table 1. Summary of machining optimization techniques.

\begin{tabular}{|c|c|c|c|}
\hline Technique & References & Tools used & Remarks \\
\hline Lagrange's method & $\begin{array}{l}\text { Brewer (1966); Bhat- } \\
\text { tacharya et al (1970) }\end{array}$ & Lagrange's multiplier & $\begin{array}{l}\text { Used for constrained opti- } \\
\text { mization }\end{array}$ \\
\hline $\begin{array}{l}\text { Geometric program- } \\
\text { ming }\end{array}$ & $\begin{array}{l}\text { Walvekar \& Lambert } \\
\text { (1970); Petropouluos } \\
\text { (1973); Gopalakrish- } \\
\text { nan \& Khayyal (1991) }\end{array}$ & $\begin{array}{l}\text { Theory is based on the } \\
\text { arithmetic-geometric } \\
\text { mean inequality }\end{array}$ & $\begin{array}{l}\text { Optimization technique } \\
\text { developed for solving } \\
\text { class of nonlinear opti- } \\
\text { mization problem espe- } \\
\text { cially found in engineering } \\
\text { design and manufacture }\end{array}$ \\
\hline Goal programming & Sundaram (1978) & $\begin{array}{l}\text { Goal programming } \\
\text { combines the logic of } \\
\text { optimization in mathe- } \\
\text { matical programming } \\
\text { with the decision } \\
\text { maker's desire to } \\
\text { satisfy several goals }\end{array}$ & $\begin{array}{l}\text { Form of multi-objective } \\
\text { optimization }\end{array}$ \\
\hline $\begin{array}{l}\text { Dynamic program- } \\
\text { ming }\end{array}$ & Agapiou (1992) & $\begin{array}{l}\text { A collection of algo- } \\
\text { rithms used to com- } \\
\text { pute optimal policies } \\
\text { given a perfect model } \\
\text { of environment }\end{array}$ & $\begin{array}{l}\text { Solving sequential } \\
\text { multi-stage decision prob- } \\
\text { lems by solving a series of } \\
\text { single variable problems }\end{array}$ \\
\hline Fuzzy logic & $\begin{array}{l}\text { Kosko (1997); Klir \& } \\
\text { Yuan (1998) }\end{array}$ & $\begin{array}{l}\text { Fuzzy interface engine } \\
\& \text { fuzzification- } \\
\text { defuzzification } \\
\text { module }\end{array}$ & $\begin{array}{l}\text { Based on a machining } \\
\text { model which works on } \\
\text { human common-sense } \\
\text { reasoning, decision- } \\
\text { making and other concepts } \\
\text { of human cognition }\end{array}$ \\
\hline Genetic algorithm & $\begin{array}{l}\text { Kuo (2002); Wang } \\
(2004)\end{array}$ & $\begin{array}{l}\text { A CGI (common gate- } \\
\text { way interface) pro- } \\
\text { gram }\end{array}$ & $\begin{array}{l}\text { Based on a machining } \\
\text { model developed from } \\
\text { theoretical analysis, } \\
\text { experimental database } \\
\text { and numerical methods }\end{array}$ \\
\hline Scatter search & Chen (2003) & $\begin{array}{l}\text { A program designed } \\
\text { by Laguna and Marti in } \\
\mathrm{C} \text { code }\end{array}$ & $\begin{array}{l}\text { A generalized optimiza- } \\
\text { tion methodology for } \\
\text { machining problems that } \\
\text { has no restrictive assump- } \\
\text { tions about objective } \\
\text { function, parameter set } \\
\text { and constraint set }\end{array}$ \\
\hline Taguchi technique & $\begin{array}{l}\text { Pignatiello (1993); } \\
\text { Tsui (1999); Singh \& } \\
\text { Kumar (2003, 2004, } \\
\text { 2005) }\end{array}$ & $\begin{array}{l}\text { Design of } \\
\text { experiments, } \\
\text { Orthogonal arrays, } \\
\text { ANOVA }\end{array}$ & $\begin{array}{l}\text { Based on actual } \\
\text { experimental work and } \\
\text { determination of optimum } \\
\text { conditions using } \\
\text { statistical tools }\end{array}$ \\
\hline $\begin{array}{l}\text { Response surface } \\
\text { methodology }\end{array}$ & $\begin{array}{l}\text { Taraman (1974); } \\
\text { Hassan \& Suliman } \\
\text { (1990); Baradie } \\
\text { (1993); Noordin } \\
\text { (2004) }\end{array}$ & $\begin{array}{l}\text { Design expert software } \\
\text { (DX6) }\end{array}$ & $\begin{array}{l}\text { Based on a machining } \\
\text { model developed by } \\
\text { mathematical and } \\
\text { statistical techniques }\end{array}$ \\
\hline
\end{tabular}


during product or process design stage are of great value. Reducing quality loss by designing the products and processes to be insensitive to variation in noise variables is a novel concept to statisticians and quality engineers.

\section{References}

Adler Y P, Markova E V, Granovsky Y V 1975 The design of experiments to find optimal conditions (Moscow: Mir Publishers)

Agapiou J S 1992 The optimization of machining operations based on a combined criterion, Part 1: The use of combined objectives in single-pass operations, Part 2: Multi-pass operations. J. Eng. Ind., Trans. ASME 114: 500-513

Ai X, Xiao S 1985 Metal cutting condition handbook (China: Mechanics Industry Press)

Ai X, Tao Q, Xiao S 1966 Metal cutting condition handbook (China: Mechanics Industry Press)

Armarego E J A, Ostafiev D 1998 A study of a proprietary computerized technological machining performance database. 8th Int. Manufacturing Conference, pp 26-33

Armarego E J A, Brown R H 1969 The machining of metals (Englewood Cliffs, NJ: Prentice Hall)

ASME 1952 Research committee on metal cutting data and bibliography. Manual on cutting of metals with single point tools 2 nd edn.

Barker T B 1990 Engineering quality by design (New York: Marcel Dekker)

Benton W C 1991 Statistical process control and the Taguchi method: A comparative evaluation. Int. J. Prod. Res. 29: 1761-1770

Bhattacharya A, Faria-Gonzalez R, Inyong H 1970 Regression analysis for predicting surface finish and its application in the determination of optimum machining conditions. Trans. Am. Soc. Mech. Eng. 92: 711

Box G E P, Hunter J S 1957 Multifactor experimental Design. J. Ann. Math. Stat. 28:

Brewer R C 1966 Parameter Selection Problem in Machining. Ann. CIRP 14: 11

Brewer R C, Rueda R 1963 A simplified approach to the optimum selection of machining parameters. Eng. Dig. 24(9): 133-150

Byrne D M, Taguchi S 1987 The Taguchi approach to parameter design. Quality Progress 20: 19-26

Chanin M N, Kuei Chu-Hua, Lin C 1990 Using Taguchi design, regression analysis and simulation to study maintenance float systems. Int. J. Prod. Res. 28: 1939-1953

Chen M, Chen K Y 2003 Determination of optimum machining conditions using scatter search. New optimization techniques in engineering, pp 681-697

Cochran G, Cox G M 1962 Experimental design (New Delhi: Asia Publishing House)

Daetz D 1987 The effect of product design on product quality and product cost. Quality Progress 20(6): 54-61

El Baradie M A 1993 Surface roughness model for turning grey cast iron (154 BHN). Proc. Inst. Mech. Eng. 207: 43-50

Ermer D S, Kromordihardjo S 1981 Optimization of multi-pass turning with constraints. J. Eng. Ind. 103: $462-468$

Ghosh S 1990 Statistical design and analysis of industrial experiments (New York: Marcel Dekker)

Gilbert W W 1950 Economics of machining. In Machining - Theory and practice. Am. Soc. Met. $476-480$

Gopalakrishnan B, Khayyal F A 1991 Machine parameter selection for turning with constraints: An analytical approach based on geometric programming. Int. J. Prod. Res. 29: 1897-1908

Hassan G A, Suliman S M A 1990 Experimental modeling and optimization of turning medium carbon steel. Int. J. Prod. Res. 28: 1057-1065

Hinduja S, Petty D J, Tester M, Barrow G 1985 Calculation of optimum cutting conditions for turning operations. Proc. Inst. Mech. Eng. 199(B2): 81-92

Johnston R E 1964 Statistical methods in foundry expts. AFS Trans. 72: 13-24

Kackar R N, Shoemaker A C 1986 Robust design: A cost effective method for improving manufacturing processes. AT \& T Tech. J. 65(Mar-Apr): 39-50 
Kamat Y V, Rao M V 1994 A Taguchi optimization of the manufacturing process for die cast components. Proc. 6th AIMTDR Conference, Bangalore, 174-179

Kasilova A G, Mescheryakov R K 1985 Technological machining handbook (Englewood Cliffs, NJ: Prentice Hall) Vol. 2

Klir G J, Yuan B 1998 Fuzzy system and fuzzy logic - theory and practice (Englewood Cliffs, NJ: Prentice Hall)

Kosko B 1997 Neural network and fuzzy systems - A dynamic approach to machine intelligence (New Delhi: Prentice Hall of India)

Kroneberg M 1966 Theory and practice for operation and development of machining process (Oxford: Pergamon)

Kuo L Y, Yen J Y 2002 A genetic algorithm based parameter-tuning algorithm for multi dimensional motion control of a computer numerical control machine tool. Proc. Inst. Mech. Eng. B216:

Lambert B K, Taraman K 1973 Development and utilization of a mathematical model of a turning operation. Int. J. Prod. Res. 11: 69-81

Lin K M, Kackar R N 1985 Wave soldering optimization by orthogonal array design method. Electrical packaging and production 108-115

Lin, Paul K H, Sullivan L P, Taguchi G 1990 Using Taguchi methods in quality engineering. Quality Progress 55-59

Moneymaker D R, Hubbard A R 1987 Loss function techniques as applied to steel foundry processes. AFS Trans. 95: 755-756

Noordin M Y et al 2004 Application of response surface methodology in describing the performance of coated carbide tools when turning AISI 1045 steel. J. Mater. Process Technol. 145: 46-58

Ostafiev D 1999 Multiple constraint optimization analysis and software for selecting machining condition on rough turning operation. Ph D thesis, University of Melbourne, Melbourne, Australia

Petropoulos P G 1973 Optimal selection of machining rate variable by geometric programming. Int. J. Prod. Res. 11: 305-314

Phadke M S 1986 Design optimization case studies. AT\&T Tech. J. 65(Mar-Apr): 51-84

Pignatiello J J 1988 An overview of the strategy and tactics of Taguchi. Inst. Ind. Eng. Trans. 20: $247-254$

Pignatiello J J 1993 Strategies for robust multi-response quality engineering. Inst. Ind. Eng. Trans. 25: 5-25

Prasad A V S R K, Rao P N, Rao U R K 1997 Optimal selection of process parameters for turning operations in a CAPP system. Int. J. Prod. Res. 35: 1495-1522

Sandvik A B 1981 Coroplan process planning software and coroplan user manual, Sandvik Automation, $\mathrm{GmbH}$

Singh H, Kumar P 2003 Quality optimization of turned parts (En24 steel) by Taguchi method. Product. J. 44: 43-49

Singh H, Kumar P 2004a Tool wear optimization in turning operation by Taguchi method. Indian J. Eng. Mater. Sci. 11: 19-24

Singh H, Kumar P 2004b Effect on power consumption for turned parts using Taguchi technique, Product. J. 45: 231-238

Singh H, Kumar P 2005 Optimizing cutting force for turned parts using Taguchi's parameter design approach. Indian J. Eng. Mater. Sci. 12: 97-103

Sundaram R M 1978 An application of goal programming technique in metal cutting. Int. J. Prod. Res. 16: 375-382

Taguchi G 1989 Quality engineering in production systems (New York: McGraw-Hill)

Taraman K 1974 Multi-machining output-multi independent variable turning research by response surface methodology. Int. J. Prod. Res. 12: 232-245

Taylor F W 1907 On the art of cutting metals. Trans. ASME 28: 31-35

Tsai P 1986 An optimization algorithm and economic analysis for a constrained machining model. $\mathrm{PhD}$ thesis, West Virginia University 
Tsui K L 1999 Robust design optimization for multiple characteristics problems. Int. J. Prod. Res. 37: 433-445

Walvekar A G, Lambert B K 1970 An application of geometric programming to machining variable selection. Int. J. Prod. Res. 8: 3

Wang X, Jawahir I S 2004 Web based optimization of milling operations for the selection of cutting conditions using genetic algorithms. Proc. Inst. Mech. Eng. 218: 212-223

Wu V 1982 Off-line quality control: Japanese quality engineering (Dearborn, MI: American Supplier Institute) 